Case Report

\title{
Sustained Remission in Patients with Primary Immune Thrombocytopenia after Romiplostim Tapering and Discontinuation: A Case Series in Real Life Management in Spain
}

\author{
María-Eva Mingot-Castellano, ${ }^{1}$ Carlos Grande-García, ${ }^{2}$ David Valcárcel-Ferreiras, ${ }^{3}$ \\ Clara Conill-Cortés, ${ }^{4}$ and Loreto de Olivar-Oliver ${ }^{4}$ \\ ${ }^{1}$ Hematology Department, Hospital Regional Universitario de Málaga, Av. de Carlos Haya, s/n, 29010 Málaga, Spain \\ ${ }^{2}$ Hematology Department, Hospital Universitario 12 de Octubre, Avda. Córdoba, s/n, 28041 Madrid, Spain \\ ${ }^{3}$ Hematology Department, Hospital Universitari Vall d'Hebron, Passeig de la Vall d'Hebron 119-129, 08035 Barcelona, Spain \\ ${ }^{4}$ Amgen S.A., Moll de Barcelona, Edifici Sud, Planta 7, 08039 Barcelona, Spain \\ Correspondence should be addressed to María-Eva Mingot-Castellano; memingot@gmail.com
}

Received 25 April 2017; Accepted 16 May 2017; Published 11 June 2017

Academic Editor: Masayuki Nagasawa

Copyright (C) 2017 María-Eva Mingot-Castellano et al. This is an open access article distributed under the Creative Commons Attribution License, which permits unrestricted use, distribution, and reproduction in any medium, provided the original work is properly cited.

\begin{abstract}
Romiplostim, a thrombopoietin-receptor agonist (TPO-ra), is a highly effective option in primary immune thrombocytopenia (ITP), with $80-90 \%$ of patients achieving platelet responses after few weeks of treatment. The evidence showing remissions, that is, sustained platelet counts after romiplostim discontinuation, in patients with ITP refractory to immunosuppressive therapy is steadily increasing. However, there is a lack of guidelines or recommendations addressing how and when to taper romiplostim in clinical practice in patients maintaining elevated and stable platelet counts. Furthermore, given the high heterogeneity of ITP patients, no associated predictive factors have been currently identified. Here, we present 4 representative clinical cases of the daily clinical practice in Spain comprising newly diagnosed, persistent, and both splenectomized and nonsplenectomized chronic ITP patients treated with romiplostim, achieving and maintaining clinical remission (platelet count $\geq 50 \times 10^{9} / \mathrm{L}$ for 24 consecutive weeks in the absence of any treatment for ITP) after treatment tapering and discontinuation, without observed safety concerns. Prospective studies identifying clinical and biological predictive factors of sustained response are warranted.
\end{abstract}

\section{Introduction}

Primary immune thrombocytopenia (ITP) is an autoimmune disease characterized by low platelets counts resulting in an increased risk of bleeding [1,2]. The pathogenesis of this chronic disorder is thought to be caused due to both platelet destruction and suboptimal platelet production $[3,4]$.

Classically, treatments focused on reducing platelet destruction in the short term (intravenous immunoglobulins, steroids, and anti-D immunoglobulin) or in the long term (rituximab and splenectomy) but failed to achieve or maintain an endurable response in certain patients and were associated with severe adverse events [5-10]. More recently, a novel generation of treatments, the thrombopoietin-receptor agonists (TPO-ras), has been developed aiming to stimulate megakaryocyte growth and increase platelets production [11, $12]$.

Romiplostim, a TPO-ra that interacts with the extracellular domain of the thrombopoietin receptor, has demonstrated rapid and sustained platelet increases in approximately $85 \%$ of both splenectomized and nonsplenectomized ITP patients, while reducing the use of concomitant medications, the requirement of splenectomy as salvage therapy, and, more importantly, the incidence of bleeding [13-17].

While the majority of patients require long-term TPOra treatment to maintain platelet responses, there is increasing evidence showing that certain patients may achieve prolonged remission after TPO-ra discontinuation [18-31]. 


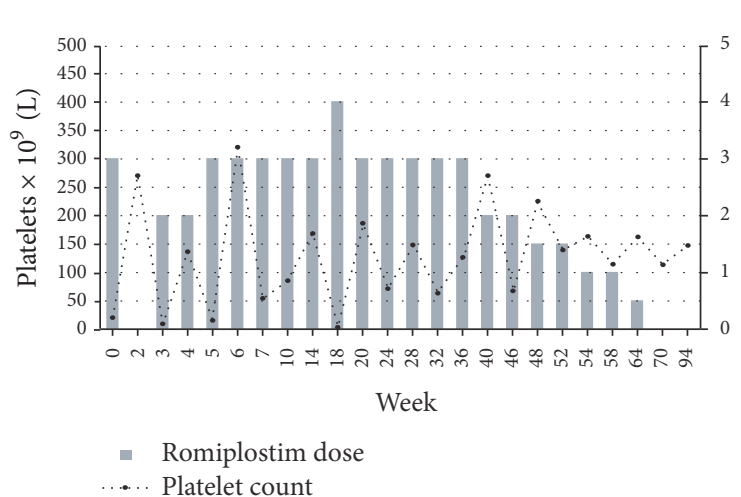

(a)

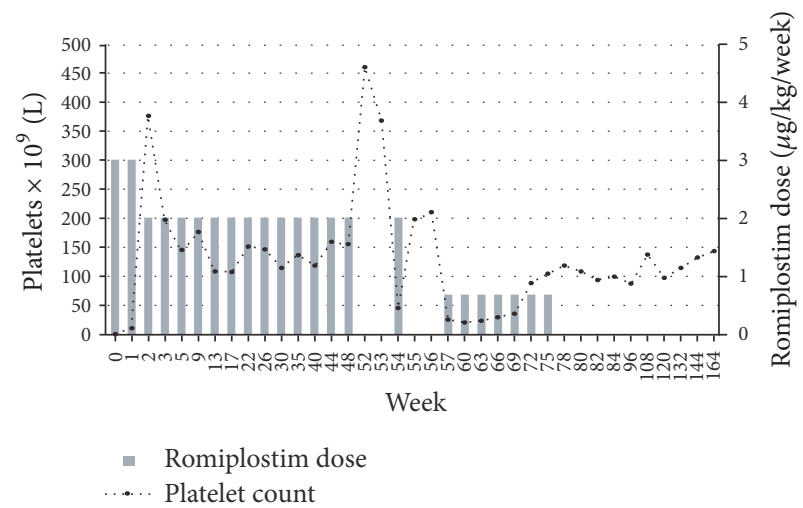

(c)

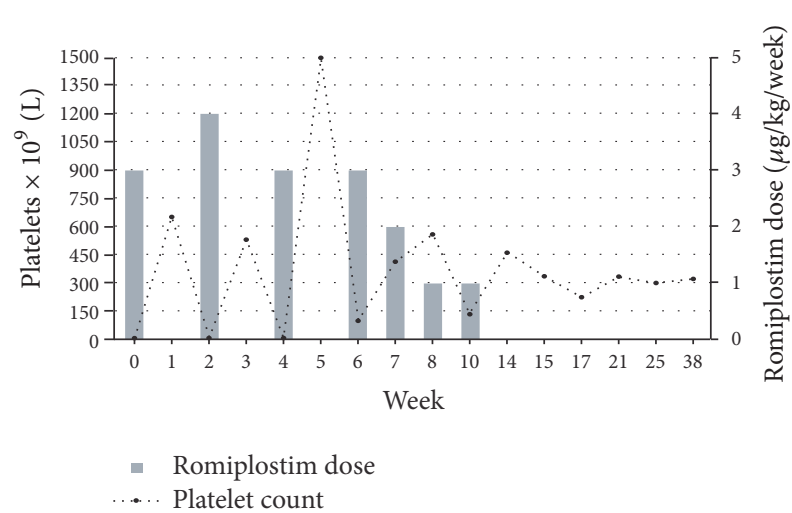

(b)

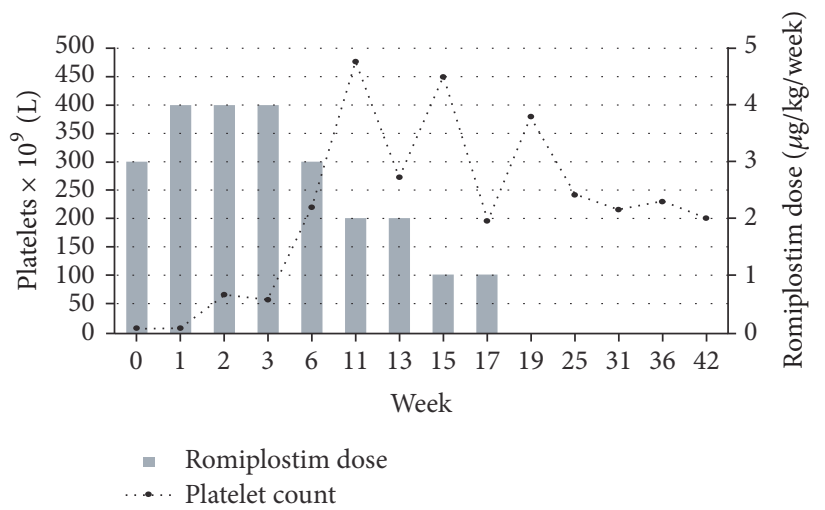

(d)

FIGURE 1: Platelet count and romiplostim dose evolution: (a) case 1: newly diagnosed ITP; (b) case 2: persistent ITP; (c) case 3: chronic ITP; splenectomized; (d) case 4: chronic ITP; nonsplenectomized.

Despite this, currently there are no unified and validated criteria or guidelines regarding how and when to taper and discontinue TPO-ra treatment in responders or a characterization of the patients that may be benefitted from this practice.

Here we report a small series of clinical cases of ITP patients refractory to immunosuppressive therapy who were treated with romiplostim. After achieving sustained responses, romiplostim was tapered and finally discontinued without relapsing occurrence to date. Our objective is to describe representative experiences of the management of these ITP patients in daily clinical practice.

\section{Case Presentation}

2.1. Case 1: Newly Diagnosed ITP. A 48-year-old man with a controlled thyroid nodule and tobacco and cannabis abuse presented with ecchymosis in his limbs by August 2014. The laboratory test found isolated thrombocytopenia (platelet count $9 \times 10^{9} / \mathrm{L}$ ) without atypical features. The bone marrow examination (aspiration and biopsy, April 2015) revealed results compatible with ITP.

$\mathrm{He}$ started prednisone $(1 \mathrm{mg} / \mathrm{Kg}$, daily). After 3 weeks of treatment, there was no response (platelet count $12 \times$ $10^{9} / \mathrm{L}$ ). Aiming to perform the thyroid nodule extirpation, immunoglobulins were also administered $(1 \mathrm{~g} / \mathrm{Kg}$ daily for 2 days). After 5 weeks with no further response (platelet count $20 \times 10^{9} / \mathrm{L}$ ), prednisone was tapered and romiplostim was started at $3 \mu \mathrm{g} / \mathrm{Kg}$, observing a rapid response after two weeks (platelets $270 \times 10^{9} / \mathrm{L}$ ). Steroids were discontinued and romiplostim was discontinued for one week, observing a new platelet decrease to $9 \times 10^{9} / \mathrm{L}$ after which romiplostim was rescheduled at $2 \mu \mathrm{g} / \mathrm{Kg}$ dose, achieving a stable platelet response and allowing the thyroid surgery (October 2014, follicular adenoma, nonmalignant). Romiplostim was maintained at $3 \mu \mathrm{g} / \mathrm{Kg}$ with stable platelet counts (Figure 1(a)) until January 2015 , when there was a platelet decrease $\left(3 \times 10^{9} / \mathrm{L}\right)$ without hemorrhagic signs, managing titrating romiplostim to $4 \mu \mathrm{g} / \mathrm{Kg}$. Helicobacter pylori was then eradicated after positive breath test.

Romiplostim continued at $3 \mu \mathrm{g} / \mathrm{Kg}$ thereafter with acceptable platelet counts $\left(30-150 \times 10^{9} / \mathrm{L}\right)$ and was initially tapered to $2 \mu \mathrm{g} / \mathrm{Kg}$ (month 9 after diagnosis; platelet count: 270 $\times 10^{9} / \mathrm{L}$ ) and further decreased by $0.5 \mu \mathrm{g} / \mathrm{Kg}$ every two months while maintaining platelet response (Figure 1(a)). The treatment was finally discontinued 16 months after ITP diagnosis, achieving its current state of remission by June 2016 (platelet count $\geq 50 \times 10^{9} / \mathrm{L}$ for 24 consecutive weeks in the absence of any treatment for ITP). No adverse events were observed. 
2.2. Case 2: Persistent ITP. A 64-year-old male was assisted in emergency department because of melena, mild hemorrhagic lesions in thorax and abdomen, asthenia, and progressive adynamia in April 2015. He had a history of tobacco abuse, ischemic stroke, and arterial hypertension and was receiving acetylsalicylic acid, atorvastatin, rizatriptan, ferrous sulfate, and losartan-hydrochlorothiazide. The blood count showed hemoglobin $7.9 \mathrm{~g} / \mathrm{dL}$ and platelet count $3 \times 10^{9} / \mathrm{L}$. The diagnosis was ITP after excluding other possibilities including bone morrow study. A digestive endoscopy revealed hiatus hernia, Schatzki ring, and severe erythematous gastritis in body and fundus. Positive results for Helicobacter pylori in stool test were obtained.

After diagnosis, aspirin was stopped, and H. pylori eradication treatment and immunoglobulins ( $1 \mathrm{~g} / \mathrm{Kg}$ daily for 2 days) were started. After 4 days without response (platelet count: $\left.10 \times 10^{9} / \mathrm{L}\right)$, the patient initiated dexamethasone $40 \mathrm{mg}$ daily for 4 days (without tranexamic acid) achieving $410 \times$ $10^{9} / \mathrm{L}$ platelets. Fourteen days after ITP diagnosis, the $H$. pylori test was negative and the platelet count decreased to $2 \times 10^{9} / \mathrm{L}$. Five additional cycles of dexamethasone were administered ( $40 \mathrm{mg}$ daily for 4 days every 15 days), not maintaining a stable response (platelet count: $1-10 \times 10^{9} / \mathrm{L}$ before dexamethasone cycles; $187-410 \times 10^{9} / \mathrm{L}$ one week after). During the fifth cycle, the patient was then hospitalized after blood transfusion due to digestive bleeding with hemodynamic angina.

Romiplostim treatment was then started at $3 \mu \mathrm{g} / \mathrm{Kg}$. High platelets response was observed after one week (platelets 649 $\left.\times 10^{9} / \mathrm{L}\right)$. Platelet count decreased to $2 \times 10^{9} / \mathrm{L}$ after 1 week without romiplostim being administered. It was reinitiated at $4 \mu \mathrm{g} / \mathrm{Kg}$ since the first platelet response was assumed to be caused by the combination of steroids and romiplostim. A new increase in platelet count $\left(528 \times 10^{9} / \mathrm{L}\right)$ was observed. After 6 weeks of intermittent administration, the platelet count remained stable at $2 \mu \mathrm{g} / \mathrm{Kg}$ (Figure $1(\mathrm{~b})$ ), and the aspirin treatment was restored. Romiplostim intervals of administration were sequentially spaced and the treatment was finally discontinued after 14 weeks of romiplostim onset, achieving its current state of remission in May 2016. No new safety signals were observed.

2.3. Case 3: Chronic ITP: Splenectomized. A 21-year-old male was diagnosed of ITP in August 2008 after presenting sustained severe mucocutaneous manifestations (age at diagnosis: 13 years old). At diagnosis, the blood count showed platelet count $5 \times 10^{9} / \mathrm{L}$ and hemoglobin $11.2 \mathrm{~g} / \mathrm{dL}$ with iron deficiency and negative direct Coombs test. After being treated with immunoglobulins and corticosteroids achieving limited response, the patient was splenectomized in July 2009 followed by a complete response, sustained for 30 months. After relapsing (severe asthenia, mucocutaneous manifestations, platelet count $12 \times 10^{9} / \mathrm{L}$, and hemoglobin $11 \mathrm{~g} / \mathrm{dL}$ ), he refused to be treated with steroid and immunoglobulin treatment was indicated $(1 \mathrm{~g} / \mathrm{Kg}$ daily for 2 days) with short-term response (platelet count $296 \times 10^{9} / \mathrm{L}$ and $12 \times 10^{9} / \mathrm{L}$ after 4 and 10 days, resp.), followed by a second cycle $(0.8 \mathrm{~g} / \mathrm{Kg}$ single dose) 21 days thereafter achieving a similar response (platelet count $134 \times 10^{9} / \mathrm{L}$ and $3 \times 10^{9} / \mathrm{L}$ after 4 and 10 days, resp.) with presence of petechiae and ecchymosis. The patient was then treated with four 15-day cycles of dexamethasone (40 mg daily for 4 days) in monotherapy without observing further response (platelet count $9 \times 10^{9} / \mathrm{L}$, without bleeding).

As he wanted to continue with an active life, at June 2013 (18 year-old; platelet count $2 \times 10^{9} / \mathrm{L}$ ) he started romiplostim $3 \mu \mathrm{g} / \mathrm{Kg}$, observing an increase in platelet count after 2 weeks to $378 \times 10^{9} / \mathrm{L}$. The patient maintained stable values of platelets between 109 and $178 \times 10^{9} / \mathrm{L}$ for 12 months with a romiplostim dose of $2 \mu \mathrm{g} / \mathrm{Kg}$ (Figure 1(c)). At the 12-month visit romiplostim was interrupted for 2 weeks, followed by a decrease in platelet count observed in the third week without treatment $\left(47 \times 10^{9} / \mathrm{L}\right)$. After romiplostim retreatment $(2 \mu \mathrm{g} / \mathrm{Kg}$ every 3 weeks) the number of platelets steadily increased (Figure 1(c)) and treatment was discontinued 18 months after romiplostim onset. After 20 months of treatment withdrawal the patient is still under clinical remission, with no safety signals observed.

2.4. Case 4: Chronic ITP: Nonsplenectomized. A 67-year-old woman with history of hypercholesterolemia, cholecystectomy, and appendectomy was diagnosed with ITP in 2000. A bone marrow aspiration and biopsy were performed with results compatible with ITP. The patient was initially treated with prednisone $(1 \mathrm{mg} / \mathrm{kg})$, achieving a sustained complete response until 2006 when she relapsed presenting concomitant hemolytic anemia (Evans syndrome) unresponsive to corticoids. She regained full response after four weekly cycles of rituximab $\left(375 \mathrm{mg} / \mathrm{m}^{2}\right)$, maintaining adequate platelet counts $\left(>100 \times 10^{9} / \mathrm{L}\right)$ during 9 years.

In July 2015, the patient presented a new episode of severe thrombocytopenia (platelet count $3 \times 10^{9} / \mathrm{L}$ ) and epistaxis, starting biweekly dexamethasone (40 $\mathrm{mg}$ daily for 4 days). After 3 cycles without observing clinical response, eltrombopag was initiated at $50 \mathrm{mg} /$ day and rapidly increased to $75 \mathrm{mg} /$ day for 3 weeks. The platelet count remained low $\left(6 \times 10^{9} / \mathrm{L}\right)$ and, in September 2015, the TPO-ra treatment was switched to romiplostim $3 \mu \mathrm{g} / \mathrm{Kg}$, observing a reduction in cutaneous bleeding diathesis, but without platelet count increases after one week. Romiplostim was then titrated to $4 \mu \mathrm{g} / \mathrm{Kg}$, with a discrete increase in platelet count observed after 2 weeks, achieving $219 \times 10^{9} / \mathrm{L}$ after 5 weeks. The dose was sequentially tapered to $3 \mu \mathrm{g} / \mathrm{Kg}$, to $2 \mu \mathrm{g} / \mathrm{Kg}$ in alternate weeks one month thereafter, and to $1 \mu \mathrm{g} / \mathrm{Kg}$ in alternate weeks by December 2015 (Figure 1(d)). Romiplostim was finally discontinued in January 2016 (platelet count $379 \times 10^{9} / \mathrm{L}$ ), achieving and maintaining remission with no new safety signals observed.

\section{Discussion}

Given the lack of published guidelines or recommendations addressing the management of patients with ITP treated with TPO-ra that achieve sustained platelet counts, reporting and sharing real-world clinical experiences are paramount. Here we report four clinical cases of adult patients with primary ITP at different stages (newly diagnosed [diagnosis 
to 3 months], persistent [3-12 months' duration], and chronic [>12 months' duration]) treated with romiplostim who achieved clinical remission, maintaining sustained platelet counts after its discontinuation (Table 1). All 4 patients had failed to multiple previous therapies but differ in the previous response. Two patients (case 1 and case 2) achieved limited/no response to previous treatments, including steroids and immunoglobulins, whereas one patient (case 3) completely responded to splenectomy, and one patient (case 4) achieved complete response to prednisone and rituximab, but not to another TPO-ra (eltrombopag). As previously observed in several trials [13-15], patients presented a very good tolerance to romiplostim, even in cases 2 and 4, which had several comorbidities that hamper their management with first-line treatments such as steroids.

Several other reports have demonstrated sustained remission and a positive safety profile after romiplostim discontinuation, mainly in chronic relapsing or refractory ITP patients. A multicenter French observational study [21] including 28 out of 54 patients with complete response after TPO-ra treatment reported $8(15 \%)$ patients remaining in sustained remission off-therapy (median follow-up after treatment discontinuation: 13,5 months; range: 5-27). Červinek et al. [24] published data of 11 out of 46 relapsed or refractory ITP patients under remission after discontinuing TPO-ra, with a median follow-up of 33 months (range: 16-54), without sideeffects observed in the long term. Santoro et al. [25] studied 39 ITP patients treated with TPO-ra after failure to one or more therapy lines observing a $13 \%(n=5)$ of persistent responders off-treatment, with a median follow-up of 2.3 years. These results have been recently reproduced in a bone marrow study [31] including 169 patients with ITP, of which $24(14 \%)$ achieved remission after a median of 52 weeks (range 6-124) of second-line romiplostim treatment. The median duration of remission during the study was 88 weeks (range 29-154), with 21 of the 24 patients still in remission at the last observation on study. A post hoc analysis [32] indicated that ITP duration $\leq 1$ year could be a potential predictor for remission, although additional studies are needed to confirm this possibility. Similar results of sustained remissions after TPOra treatment and discontinuation have also been reported in several small case series of ITP patients [18-20, 22, 27-29, 33].

An integrated analysis of eight romiplostim ITP trials ( $n=949$ ) was performed by Bussel et al. [34]. Twentyseven patients maintained platelet counts of $\geq 50 \times 10^{9} / \mathrm{L}$ for $\geq 26$ consecutive weeks without any treatment for ITP. The median time from initiation of romiplostim treatment to onset of remission was 31 weeks (range, 3.1-181 weeks) and the median duration of remission was 42 weeks (range, 26-174 weeks). The short follow-up of some of the included trials and the high platelet count required to interrupt romiplostim $\left(>400 \times 10^{9} / \mathrm{L}\right.$ in most trials) may have restricted these results.

There is additional evidence regarding newly diagnosed or persistent ITP patients achieving remission after TPOra treatment. A prospective (12-month follow-up), singlearm, phase II trial recently published by Newland et al. [30] included 75 patients with ITP diagnosed within 6 months of romiplostim onset (median: 2.2 months) who failed to at least one first-line treatment. Twenty-four out of 75 (32\%) patients achieved clinical remission (platelet counts of $\geq 50 \times$ $10^{9} / \mathrm{L}$ for 24 consecutive weeks without any ITP treatment). Mean platelet count for the first 2 months was associated with remission. A retrospective analysis of 260 patients with primary ITP reported by González-López et al. [35] observed 80 patients who discontinued eltrombopag after achieving a complete remission (platelet count $>100 \times 10^{9} / \mathrm{L}$ ). Twentysix out of $49(53 \%)$ evaluable patients showed sustained response (median follow-up: 9 months; range: 6-25) after discontinuing eltrombopag, with 4 patients being categorized as persistent ITP.

Carpenedo et al. [23] reported 13/27 responders who discontinued romiplostim after a mean of 44.3 weeks on therapy with sustained response maintained for a mean of 26 months. Three and 4 patients were newly diagnosed and persistent, respectively, and their long-term responses were proposed to be spontaneous. Whether our recently diagnosed patients were spontaneous responders remains unclear. Interestingly, there is a differential characteristic between them. While case 1 started remission after 16 months of romiplostim onset, case 2 started remission after 14 weeks. However, this has not been identified as a predictive factor in the published evidence.

The mechanisms and factors of remission in patients with ITP remain unknown, although some studies suggest a restoration of immune tolerance and a decrease of inflammatory state after continuous treatment with TPOra through the stimulation of regulatory $\mathrm{B}$ and $\mathrm{T}$ (T-reg) lymphocytes, as measured by the suppression of autologous CD4(+) CD25(-) cells' proliferation and the reduction of interleukin-2-producing CD4(+)_cells $[36,37]$. On the other hand, circulating transforming growth factor- $\beta 1$ (TGF- $\beta 1$ ) is essential to preserve T-reg functions, inducing forkhead box protein 3 (Foxp3) expression and converting T-regs Foxp3(-) to Foxp3(+) [38]. In patients treated with TPOra agents, TGF- $\beta 1$ levels increase while soluble CD40-ligand (sCD40L) levels decrease [36, 39], suggesting a reduction in the overall inflammatory state and supporting the nonactivation of platelets in these patients [40]. Furthermore, in patients under TPO-ra treatment, a significant elevation in $F c \gamma$ receptor $(\mathrm{F} c \gamma \mathrm{R})$ IIb and a decrease in $\mathrm{Fc} \gamma \mathrm{R}$ I and IIa levels have been observed [41]. Fc $\gamma \mathrm{R}$ is a heterogeneous group of cell-surface glycoproteins that provide links between humoral and cellular immunity. An elevated expression of the activating $\mathrm{Fc} \gamma \mathrm{R}$ I and IIa along with decreased expression of the inhibitory Fc $\gamma$ R IIb is involved in the pathogenesis of ITP [42]. In vitro phagocytosis assays show that a shift in the balance of $\mathrm{F} c \gamma \mathrm{R}$ toward inhibitory $\mathrm{F} c \gamma \mathrm{R}$ IIb on monocytes was accompanied with a considerable decrease in monocyte/macrophage phagocytic capacity in patients with ITP treated with TPO-ra [41]. Modulation of monocyte Fc $\gamma$ R balance by TPO-ra was also found in a murine model of ITP established by transferring splenocytes from immunized CD61 knockout mice into CD611 severe combined immunodeficient mice. Romiplostim administration in ITP mice significantly upregulated inhibitory $\mathrm{Fc} \gamma \mathrm{R}$ II expression and downregulated activating Fc $\gamma$ R I expression [41]. Further analyses are warranted of whether these two mechanisms of 


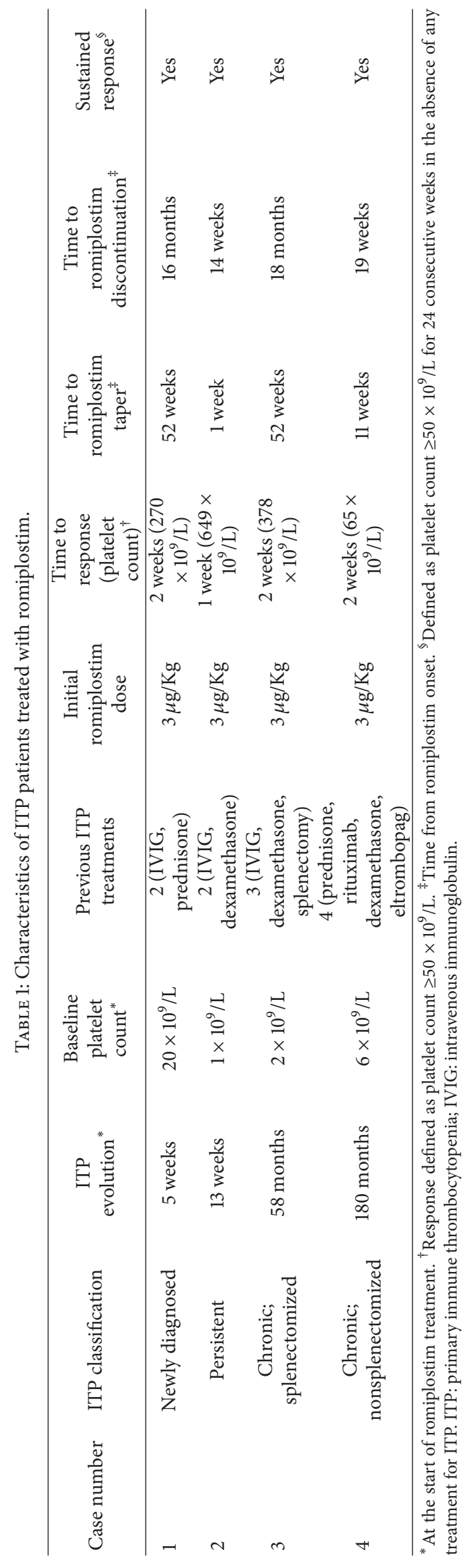


action of TPO-ra are interconnected or if there are additional mechanisms involved.

Despite the differential characteristics of the described patients (Table 1), platelet responses were rapidly observed after romiplostim treatment (1-2 weeks) in all cases, with lower TPO-ra doses compared with the mean doses administered in the efficacy trials $[14,16]$. Several other reports had observed similar low doses in long-term remitters [18-20, 22, $24,30]$, being comparatively higher in patients not achieving stable platelets counts and subsequent discontinuation [24]. However, a direct causality between administered doses and remission status was not established.

Although it is widely used in clinical practice as secondor third-line treatment in ITP, there are still no guidelines addressing the management of romiplostim in responder patients. Given its high variability, the treatment and followup of ITP patients should be personalized and the final judgment should be made after an exhaustive characterization of individual circumstances. In this regard, the published evidence failed to identify predictive factors of remission after TPO-ra treatment [21-23, 34, 35] besides a higher platelet count in the first two months of treatment observed by Newland et al. in patients achieving remission [30] and, potentially, an ITP duration $\leq 1$ year [32].

The dose tapering described in the registration trials $[13,16]$ has been slightly redefined in subsequent long-term extensions [15] and is the current standard of care for ITP patients treated with romiplostim achieving platelet response. Generally, in clinical practice, romiplostim is withheld if platelets count is over $250-400 \times 10^{9} / \mathrm{L}$, with dose and intervals adjustments at the physician's discretion to maintain target platelet counts. The maintenance of stable platelet counts after treatment discontinuation was either described in the short term to mid-term [18-20] (cases 2 and 4) or in the long term [22-24] (cases 1 and 3), suggesting different physiological responses to romiplostim in ITP patients and bolstering the importance of a close follow-up and treatment titration in these patients. Functional T-regs normalization might have already been induced in these patients through TPO-ra. Accordingly, TPO-ra administration has to be adjusted, aiming to fully restore platelet counts and to achieve stable T-reg populations, establishing long-term immune tolerance. As mentioned, in clinical practice, required doses and intervals are expected to differ between patients, and the minimal effective dose to maintain adequate platelet levels should be determined individually. This adjustment to the minimum effective dose should be closely monitored, with observation periods between dose modifications noninferior to 2-4 weeks to be aware about platelets counts stability.

In summary, there is an increasing evidence of patients with ITP achieving remission after romiplostim tapering and discontinuation. This might represent a paradigm shift for these patients traditionally requiring chronical treatments. The identification of predictive associated factors in prospective long-term trials is warranted, aiming to generate unified recommendations for the treatment and management of these patients in daily clinical practice.

\section{Consent}

Consent was obtained from the included patients for publication of this case report series.

\section{Conflicts of Interest}

María Eva Mingot Castellano has received honoraria for lectures and consulting activities by Baxter, Pfizer, Bayer, Novo Nordisk, Novartis, and Amgen. Carlos Grande has received honoraria for lectures by Amgen and for participating in advisory boards sponsored by Amgen, Celgene, Janssen, and Shire; David Valcarcel has received honoraria for lectures and for participating in advisory boards sponsored by Amgen and Novartis; Loreto de Olivar and Clara Conill are fulltime employees of Amgen S.A. and may own Amgen stock and/or stock options. Medical writing assistance was funded by Amgen S.A. and provided by Juan Martín from TFS Develop.

\section{Acknowledgments}

This work was supported by Amgen S.A.

\section{References}

[1] D. B. Cines and V. S. Blanchette, "Medical progress: immune thrombocytopenic purpura," The New England Journal of Medicine, vol. 346, no. 13, pp. 995-1008, 2002.

[2] C. Neunert, W. Lim, M. Crowther, A. Cohen, L. Solberg Jr., and M. A. Crowther, "The American Society of Hematology 2011 evidence-based practice guideline for immune thrombocytopenia," Blood, vol. 117, no. 16, pp. 4190-4207, 2011.

[3] P. J. Ballem, G. M. Segal, J. R. Stratton, T. Gernsheimer, J. W. Adamson, and S. J. Slichter, "Mechanisms of thrombocytopenia in chronic autoimmune thrombocytopenic purpura. Evidence of both impaired platelet production and increased platelet clearance," Journal of Clinical Investigation, vol. 80, no. 1, pp. 3340, 1987.

[4] H. Louwes, O. A. Z. Lathori, E. Vellenga, and J. T. M. De Wolf, "Platelet kinetic studies in patients with idiopathic thrombocytopenic purpura," American Journal of Medicine, vol. 106, no. 4, pp. 430-434, 1999.

[5] R. M. Jiji, T. Firozvi, and C. L. Spurling, "Chronic Idiopathic Thrombocytopenic Purpura: Treatment With Steroids and Splenectomy," Archives of Internal Medicine, vol. 132, no. 3, pp. 380-383, 1973.

[6] A. C. Newland, J. G. Treleaven, R. M. Minchinton, and A. H. Waters, "High-dose intravenous IgG in adults with autoimmune thrombocytopenia," The Lancet, vol. 321, no. 8316, pp. 84-87, 1983.

[7] A. Salama, C. Mueller-Eckhardt, and V. Kiefel, "Effect of intravenous immunoglobulin in immune thrombocytopenia," The Lancet, vol. 322, no. 8343, pp. 193-195, 1983.

[8] G. J. den Ottolander, J. W. Gratama, J. de Koning, and A. Brand, "Long-term follow-up study of 168 patients with immune thrombocytopenia. implications for therapy," Scandinavian Journal of Haematology, vol. 32, no. 1, pp. 101-110, 1984.

[9] J. Pizzuto and R. Ambriz, “Therapeutic experience on 934 adults with idiopathic thrombocytopenic purpura: Multicentric trial 
of the Cooperative Latin American Group on Hemostasis and Thrombosis," Blood, vol. 64, no. 6, pp. 1179-1183, 1984.

[10] R. Stasi, A. Pagano, E. Stipa, and S. Amadori, "Rituximab chimeric anti-CD20 monoclonal antibody treatment for adults with chronic idiopathic thrombocytopenic purpura," Blood, vol. 98, no. 4, pp. 952-957, 2001.

[11] J. B. Bussel, D. J. Kuter, J. N. George et al., "AMG 531, a thrombopoiesis-stimulating protein, for chronic ITP," New England Journal of Medicine, vol. 355, no. 16, pp. 1672-1681, 2006.

[12] J. M. Jenkins, D. Williams, Y. Deng et al., "Phase 1 clinical study of eltrombopag, an oral, nonpeptide thrombopoietin receptor agonist," Blood, vol. 109, no. 11, pp. 4739-4741, 2007.

[13] D. J. Kuter, J. B. Bussel, R. M. Lyons et al., "Efficacy of romiplostim in patients with chronic immune thrombocytopenic purpura: a double-blind randomised controlled trial," The Lancet, vol. 371, no. 9610, pp. 395-403, 2008.

[14] D. J. Kuter, M. Rummel, R. Boccia et al., "Romiplostim or standard of care in patients with immune thrombocytopenia," New England Journal of Medicine, vol. 363, no. 20, pp. 1889-1899, 2010.

[15] D. J. Kuter, J. B. Bussel, A. Newland et al., "Long-term treatment with romiplostim in patients with chronic immune thrombocytopenia: Safety and efficacy," British Journal of Haematology, vol. 161, no. 3, pp. 411-423, 2013.

[16] J. B. Bussel, D. J. Kuter, V. Pullarkat, R. M. Lyons, M. Guo, and J. L. Nichol, "Safety and efficacy of long-term treatment with romiplostim in thrombocytopenic patients with chronic ITP," Blood, vol. 113, no. 10, pp. 2161-2171, 2009.

[17] T. B. Gernsheimer, J. N. George, L. M. Aledort et al., "Evaluation of bleeding and thrombotic events during long-term use of romiplostim in patients with chronic immune thrombocytopenia (ITP)," Journal of Thrombosis and Haemostasis, vol. 8, no. 6, pp. 1372-1382, 2010.

[18] E. Vlachaki, V. Papageorgiou, F. Klonizakis et al., "Total remission of severe immune thrombocytopenia after short term treatment with romiplostim," Hematology Reports (formerly Hematology Reviews), vol. 3, article e20, 2011.

[19] B. Ghadaki, I. Nazi, J. G. Kelton, and D. M. Arnold, "Sustained remissions of immune thrombocytopenia associated with the use of thrombopoietin receptor agonists," Transfusion, vol. 53, no. 11, pp. 2807-2812, 2013.

[20] J. Thachil, I. Salter, and J. N. George, "Complete remission of refractory immune thrombocytopenia (ITP) with a short course of Romiplostim," European Journal of Haematology, vol. 91, no. 4, pp. 376-377, 2013.

[21] M. Mahévas, O. Fain, M. Ebbo et al., "The temporary use of thrombopoietin-receptor agonists may induce a prolonged remission in adult chronic immune thrombocytopenia. Results of a French observational study," British Journal of Haematology, vol. 165, no. 6, pp. 865-869, 2014.

[22] D. Provan, L. Taylor, R. Nandigham, U. Doobaree, P. Kalkur, and A. Newland, "Sustained responses following treatment with romiplostim in immune thrombocytopenia: a single-centre experience," J Hematol Thromboembolic Dis, vol. 2, p. 147, 2014.

[23] M. Carpenedo, S. Cantoni, V. Coccini, M. Fedele, E. Morra, and E. M. Pogliani, "Feasibility of romiplostim discontinuation in adult thrombopoietin-receptor agonist responsive patients with primary immune thrombocytopenia: an observational retrospective report in real life clinical practice," Hematology Reports, vol. 7, no. 1, pp. 1-4, 2015.
[24] L. Červinek, J. Mayer, and M. Doubek, "Sustained remission of chronic immune thrombocytopenia after discontinuation of treatment with thrombopoietin-receptor agonists in adults," International Journal of Hematology, vol. 102, no. 1, pp. 7-11, 2015.

[25] C. Santoro, F. De Angelis, E. Baldacci et al., "Thrombopoietin receptor agonists in primary immune thrombocytopenia: evaluation of efficacy (response and sustained response offtreatment) and safety in a single center population," Haematologica, pp. 99-211, 2014.

[26] J. Bussel, F. Rodeghiero, and R. M. Lyons, "Sustained hemostatic platelet counts in adults with immune thrombocytopenia (ITP) following cessation of treatment with the TPO receptor agonist romiplostim: report of 9 cases," in Blood, vol. 118, p. 3281, 2011.

[27] A. Baxley, J. George, D. Terrell, M. Moorman, and J. Holter, “A case report of long-term complete remission following cessation of romiplostim dosing in a previously severe ITP patient. J Clin Oncol," in J Clin Oncol, vol. 30, 2012.

[28] F. Biondo, C. Santoro, E. Baldacci, A. Leporace, R. Foa, and M. Mazzucconi, "Persistent response after romiplostim discontinuation in patients affected by primary thrombocytopenia," in Haematologica, vol. 97, p. 428, 2012.

[29] M. Perera, A. Suarez, H. Luzardo, J. Lopez, and T. Molero, "Spontaneous remission after a year of romiplostim in an adult patient with refractory primary immune thrombocytopenia," Annals of Hematology, vol. 91, no. 9, pp. 1497-1498, 2012.

[30] A. Newland, B. Godeau, V. Priego et al., "Remission and platelet responses with romiplostim in primary immune thrombocytopenia: Final results from a phase 2 study," British Journal of Haematology, vol. 172, no. 2, pp. 262-273, 2016.

[31] A. Janssens, F. Rodeghiero, D. Anderson et al., "Changes in bone marrow morphology in adults receiving romiplostim for the treatment of thrombocytopenia associated with primary immune thrombocytopenia," Annals of Hematology, vol. 95, no. 7, pp. 1077-1087, 2016.

[32] A. Janssens, L. Červinek, M. Tejeda Romero, X. Wang, and M. Eisen, "Characterization of patients with immune thrombocytopenia (ITP) entering remission in a romiplostim bone marrow study," http://Learningcenter.ehaweb.org/eha/ 2016/21st/133392/ann.janssens.characterization.of.patients.with .immune.thrombocytopenia.28itp29.html?f=p6m3e968o12159.

[33] L. Torres Miñana, M. Perera, M. Torres Ochando, H. Luzardo, and T. Molero Labarta, "Sustained responses following stopped treatment with romiplostim in immune thrombocytopenia: a single-centre experience," 2016, http://Learningcenter.ehaweb .org/eha/2016/21st/134985/Laura.torres.miana.sustained.responses.following.stopped.treatment.with.html?f=p6m3e968o12159.

[34] J. B. Bussel, X. Wang, A. Lopez, and M. Eisen, "Case study of remission in adults with immune thrombocytopenia following cessation of treatment with the thrombopoietin mimetic romiplostim †," Hematology, vol. 21, no. 4, pp. 257-262, 2016.

[35] T. J. González-López, C. Pascual, M. T. Álvarez-Román et al., "Successful discontinuation of eltrombopag after complete remission in patients with primary immune thrombocytopenia," American Journal of Hematology, vol. 90, no. 3, pp. E40E43, 2015.

[36] W. Bao, J. B. Bussel, S. Heck et al., "Improved regulatory Tcell activity in patients with chronic immune thrombocytopenia treated with thrombopoietic agents," Blood, vol. 116, no. 22, pp. 4639-4645, 2010. 
[37] H. Zhong, W. Bao, X. Li et al., "CD16+ monocytes control T-cell subset development in immune thrombocytopenia.," Blood, vol. 120, no. 16, pp. 3326-3335, 2012.

[38] Y. Y. Wan and R. A. Flavell, "'Yin-Yang' functions of transforming growth factor- $\beta$ and $\mathrm{T}$ regulatory cells in immune regulation," Immunological Reviews, vol. 220, no. 1, pp. 199-213, 2007.

[39] M. Nagahama, S. Nomura, S. Kanazawa, Y. Ozaki, H. Kagawa, and S. Fukuhara, "Significance of chemokines and soluble CD40 ligand in patients with autoimmune thrombocytopenic purpura," European Journal of Haematology, vol. 69, no. 5-6, pp. 303-308, 2002.

[40] B. Psaila, J. B. Bussel, M. D. Linden et al., "In vivo effects of eltrombopag on platelet function in immune thrombocytopenia: No evidence of platelet activation," Blood, vol. 119, no. 17, pp. 4066-4072, 2012.

[41] X.-G. Liu, S. Liu, Q. Feng et al., “Thrombopoietin receptor agonists shift the balance of Fcg receptors toward inhibitory receptor IIb on monocytes in ITP," Blood, vol. 128, no. 6, pp. 852-861, 2016.

[42] M. Guilliams, P. Bruhns, Y. Saeys, H. Hammad, and B. N. Lambrecht, "The function of Fc $\gamma$ receptors in dendritic cells and macrophages," Nature Reviews Immunology, vol. 14, no. 2, pp. 94-108, 2014. 


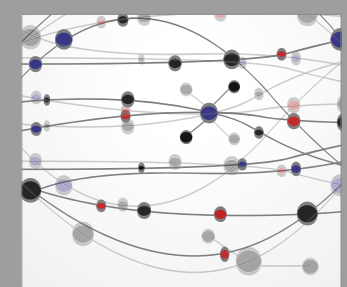

The Scientific World Journal
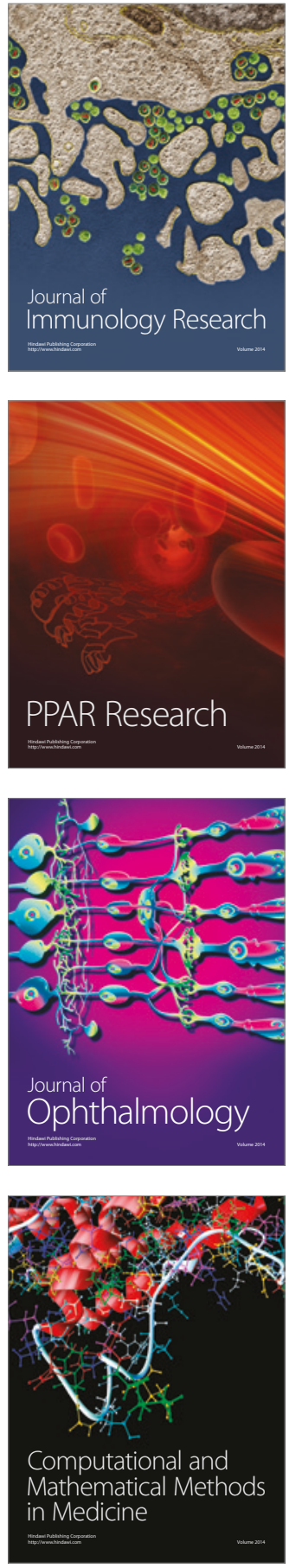

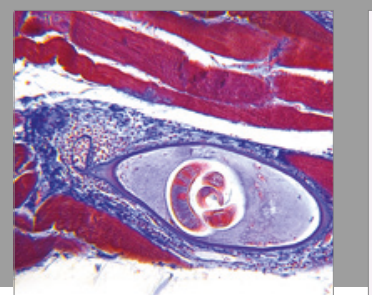

Gastroenterology Research and Practice
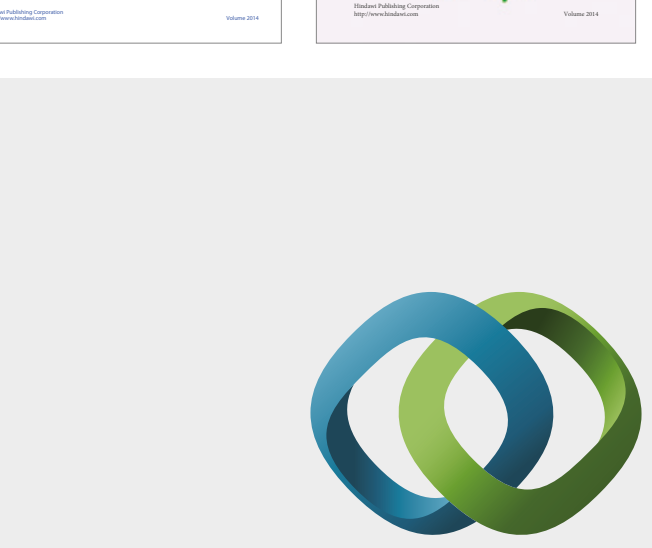

\section{Hindawi}

Submit your manuscripts at

https://www.hindawi.com
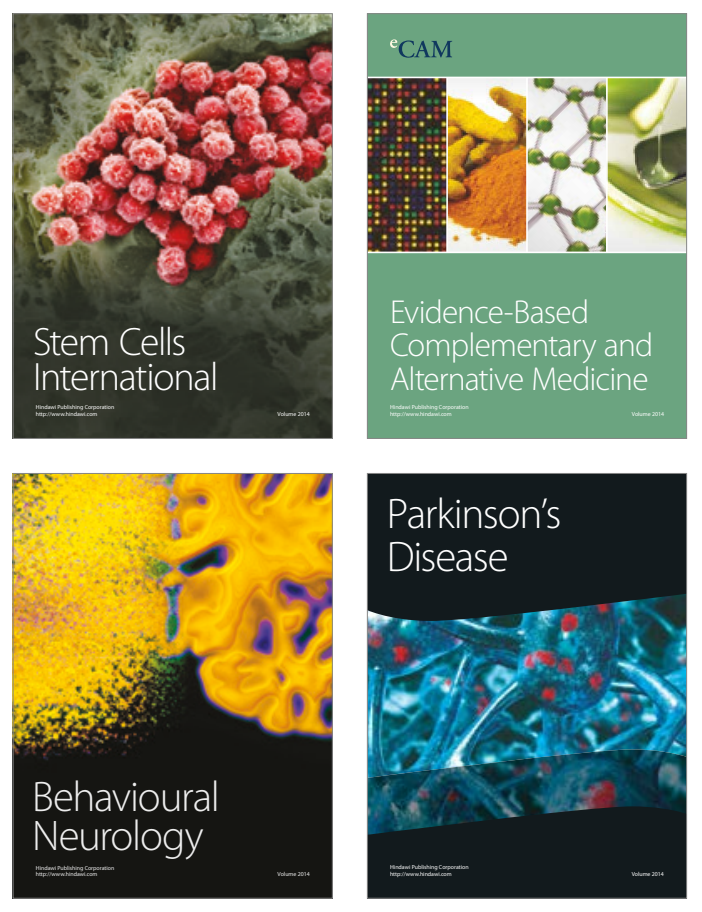
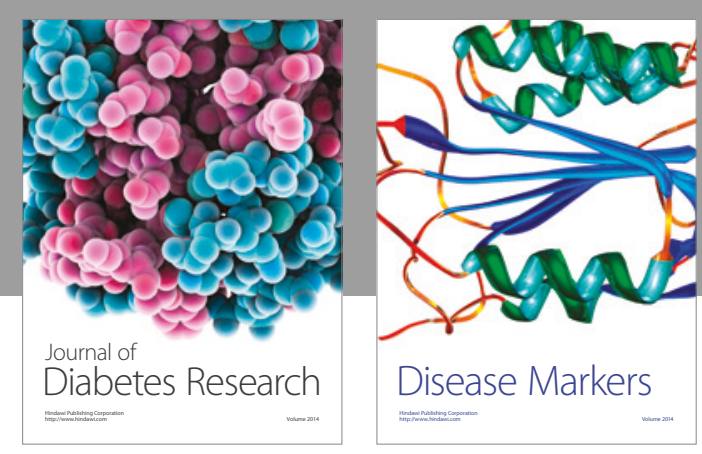

Disease Markers
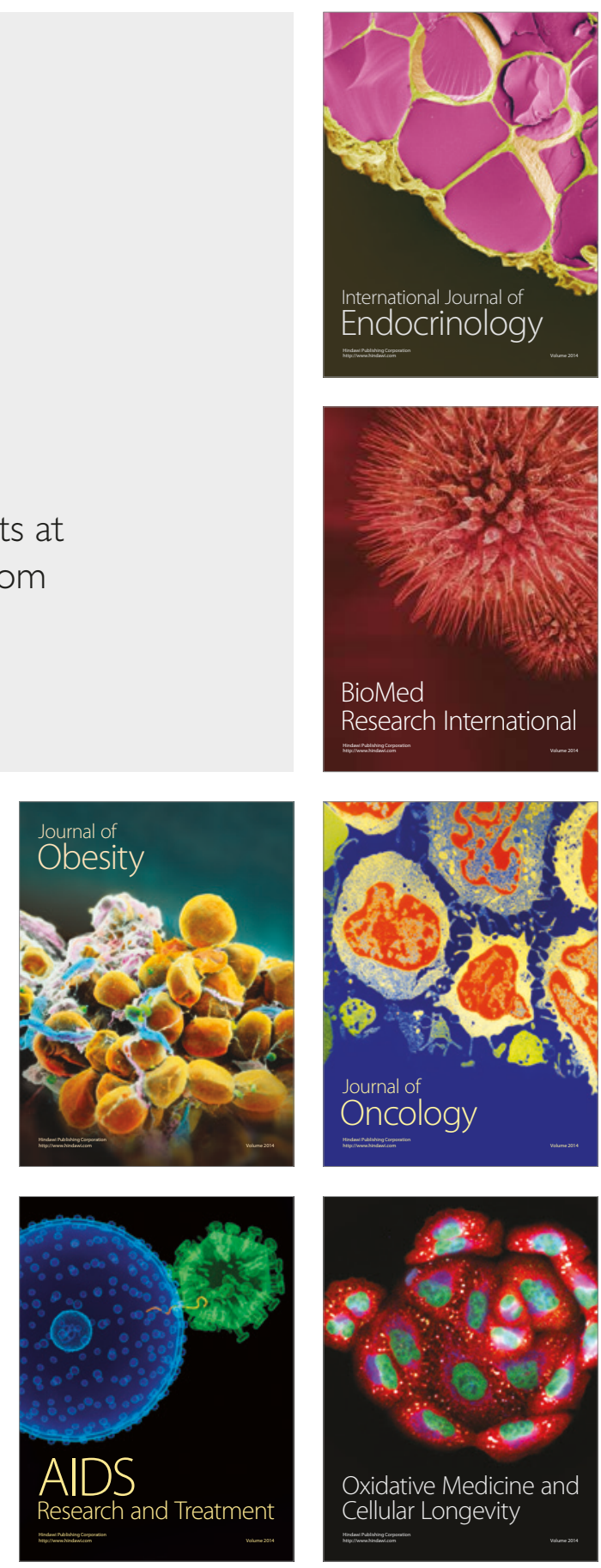